\title{
Can Laparoscopic Cholecystectomy be a Feasible Standard in a Rural set up too? - An Experience of 348 cases from a Peripheral set up of Western Nepal.
} Shrestha AL, Shrestha P, Brown D

Department of General Surgery

United Mission Hospital,

Tansen, Palpa, Nepal.

\section{Corresponding Author}

Ashish Lal Shrestha

Department of General Surgery

United Mission Hospital,

Tansen, Palpa, Nepal.

E-mail: butchgrunty@yahoo.com

\section{Citation}

Shrestha AL, Shrestha P, Brown D. Can Laparoscopic Cholecystectomy be a Feasible Standard in a Rural set up too? - An Experience of 348 cases from a Peripheral set up of Western Nepal. Kathmandu Univ Med J 2015;50(2):130-3.

\section{ABSTRACT}

\section{Background}

Gall stone disease is a common reason for admissions in both acute and elective situations and bears significant morbidity in the rural population of western Nepal. The earlier conventional open method of treatment for the same seems to have been largely seeded by the laparoscopic approach owing to its numerous benefits.

\section{Objective}

To study the clinical profile of patients with symptomatic gall stones with respect to demography and to assess the feasibility of using Laparoscopic cholecystectomy as the next standard in this set up too as guided by the outcome in terms of complications, conversion rates and potential impact it bears on the health and socioeconomic status in this group.

\section{Method}

A retrospective analysis of all the patients undergoing an attempted laparoscopic cholecystectomy from $1^{\text {st }}$ Jestha 2068 to $30^{\text {th }}$ Jestha 2070 was done. Relevant medical records were reviewed to study demography, various indications for operations, intra operative events including conversions and complications.

\section{Result}

Of 348 patients $293(84.19 \%)$ were females and $55(15.80 \%)$ were males. The mean age was 38.46 years (range 15-76 years). Most of the patients belonged to the Palpa district of Lumbini zone and many were from other surrounding areas. Gall stone disease was commonest in people of Brahmin ethnicity. The operating time was $<2$ hours for most and most had an uneventful recovery with a mean hospital stay of 3.8 days. The rate of conversion to open cholecystectomy was $6.9 \%$ (24 out of 348 patients). Post operative complications were noted in 5 patients (1.42\%). Of these 1 sustained a major bile duct injury $(0.28 \%)$ requiring immediate conversion and repair, 3 had post operative bilioma and 1 had diffuse bleeding from the gall bladder fossa all requiring re explorations. There was no mortality in this study.

\section{Conclusion}

Laparoscopic cholecystectomy is a safe, reliable and a promising option even in the rural peripheral set up. Due to its well known advantages and superiority over the open conventional method and considering the impact that it holds on the overall outcome, morbidity, health and socioeconomic status of the rural population, it can be recommended as an acceptable feasible standard in rural peripheral set up.

\section{KEY WORDS}

Complications, conversions, laparoscopic cholecystectomy. 


\section{INTRODUCTION}

Cholelithiasis exerts a considerable disease burden globally. ${ }^{1,2}$ Reports state an overall prevalence of $10-15 \%$ in USA, $18.5 \%$ in Europe and around or below $5 \%$ in most of the Asian and African countries. ${ }^{2,3}$ There seems to be a significant number of hospital admissions in our country annually due to gallstones and its related complications. A study reports an overall prevalence of $4.78 \%$ in Nepal. ${ }^{4}$

The accepted current method as a gold standard for treatment of symptomatic gallstone disease is laparoscopic cholecystectomy. ${ }^{5,6}$ An estimated $90 \%$ of cholecystectomies are now performed by the laparoscopic approach worldwide. ${ }^{5}$ Numerous benefits of laparoscopic method over conventional open technique are known, a few of which are:

1. earlier return of bowel function

2. less post operative pain

3. improved cosmesis

4. shorter length of hospital stay

5. early return to full activity and

6. decreased overall cost. ${ }^{5,7-11}$ This distinguishes the laparoscopic approach clearly as a desirable method. Yet a varying percentage of these end up in conversions as dictated by diverse clinical situations and operative findings. The conversion rates in most series ranges from 1.8-7.8\% and seems more common in the elderly and in the setting of acute cholecystitis. ${ }^{5}$

While executing a successful laparoscopic procedure is advantageous to the patient in multiple ways, on the other hand a great deal of caution and care is necessary to avoid serious technical errors that could lead to devastating complication like major bile duct injury. Most cases report bile duct injuries ranging from $0.4-0.7 \%$ and morbidity rates ranging from $1.5-8.6 \% .^{5,12}$ This study aims to understand the feasibility and relevance of such a procedure in terms of outcome and its impact on the rural health at a peripheral set up of western Nepal. We hereby present our data analysis on patient demography, various indications for operations, intra operative events including conversions and complications.

\section{METHODS}

A retrospective analysis was done at United Mission Hospital, Tansen of rural Western Nepal between $1^{\text {st }}$ Jestha 2068 to $30^{\text {th }}$ Jestha 2070 . A total of 348 patients were included. All the relevant medical records pertaining to the patients who underwent laparoscopic cholecystectomy were reviewed and data collected, subsequently. Institutional approval was obtained. The study included patients belonging to the age groups 14 and above who had an attempted laparoscopic cholecystectomy for various indications namely:

1. biliary colic

2. symptomatic gall stones with associated polyps

3. acute calculous cholecystitis

The exclusions were made for:

1. acalculous cholecystitis

2. choledocholithiasis

3. instrumental malfunction

Preoperatively patients were investigated with hemoglobin, blood group type, serum creatinine, liver function tests and an abdominal ultrasound to confirm findings.

Additionally, blood sugar, chest $x$ ray and ECG were done for those beyond 45 years or above as indicated by their clinical findings.

All the patients were given a single dose of prophylactic antibiotic intravenously and all the procedures were attempted under general anesthesia. Standard 4 port technique was used in all. The pneumoinsufflation was achieved using Veress needle in 124 patients and in the rest using Hasson's open technique. The intra operative events were recorded including the operative findings, time and intra operative complications and difficulties that mandated conversion to conventional open operation. All the patients were observed for immediate and delayed complications. The outcome was evaluated in terms of patient demography, intra operative events, conversion rates, complications and morbidity. This was interpreted in light of relevance of such a procedure in a rural peripheral set up and its continuation as a feasible standard.

The results were analyzed using Microsoft Excel.

\section{RESULTS}

Out of 348 cases, 293(84.19\%) were females and $55(15.80 \%)$ were males. The mean age was 38.46 years (range $15-76$ years).

Most of the patients belonged to the Palpa district of Lumbini zone and many were from other surrounding areas as shown in Table1 and Figure 1.

Table 1. Geographical distribution of patients with gall stone disease $(n=348)$

\begin{tabular}{|lc|}
\hline Zones & Patient No. \\
\hline Lumbini & 302 \\
\hline Gandaki & 27 \\
\hline Rapti & 13 \\
\hline Dhaulagir & 4 \\
\hline Janakpur & 1 \\
\hline Mahakali & 1 \\
\hline Total & 348 \\
\hline
\end{tabular}




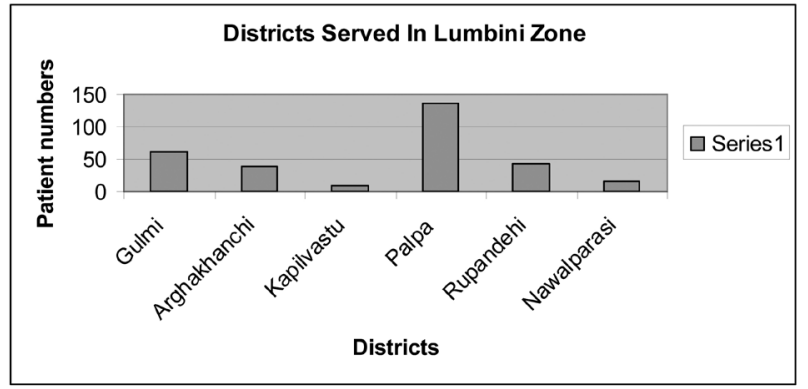

Graph 1. District wise distribution of patients with gall stone disease in Lumbini Zone. $(n=302)$

Gall stone disease was commonest in people of Brahmin ethnicity as shown in Table 2.

Table 2. Distribution of gall stone disease based on ethnicity ( $n=348)$

\begin{tabular}{|lc|}
\hline Ethnicity & Number \\
\hline Brahmin & 121 \\
\hline Magar & 95 \\
\hline Chettri & 45 \\
\hline Newar & 17 \\
\hline Gurung & 6 \\
\hline Tharu & 4 \\
\hline Rai & 3 \\
\hline Others & 57 \\
\hline Total & $\mathbf{3 4 8}$ \\
\hline
\end{tabular}

The operating time was $<2$ hours for most of the patients as shown in Table 3. Most of the patients had an uneventful recovery and a mean hospital stay of 3.8 days.

Table 3. Distribution of operating time $(n=348)$

\begin{tabular}{|lc|}
\hline Patient No. & Time \\
\hline 36 & $>2$ hours \\
\hline 193 & $</=2$ hours \\
\hline 119 & $</=1$ hour \\
\hline 348 & \\
\hline
\end{tabular}

However some patients required conversion, the decision of which was based mainly on intra operative findings. The rate of conversion to conventional open cholecystectomy was $6.9 \%$ (24 out of 348 patients) as shown in Table 4.

Table 4. Distribution of reasons for conversion $(n=24)$

\begin{tabular}{|lcc|}
\hline Reasons for conversion to open cholecystectomy & N & $\%$ \\
\hline $\begin{array}{l}\text { Dense inflammatory adhesions and poor display of } \\
\text { Calot's } \Delta \text { anatomy }\end{array}$ & 10 & 41.60 \\
\hline Acute inflammation (acute calculous cholecystitis) & 7 & 29.10 \\
\hline Obscure anatomy & 3 & 12.50 \\
\hline Bleeding from Gall bladder bed & 2 & 8.30 \\
\hline Common Bile Duct injury & 1 & 4.16 \\
\hline Gall bladder empyema & 1 & 4.16 \\
\hline Total & $\mathbf{2 4}$ & \\
\hline
\end{tabular}

Post operative complications were noted in five patients $(1.42 \%)$ as listed on the table 5 . Of these 1 sustained a major bile duct injury $(0.28 \%)$ that was recognized intra operatively and repaired over a $\mathrm{T}$ tube.

Table 5. Distribution of complications $(n=5)$

\begin{tabular}{|lll|}
\hline Complications & N & \% \\
\hline Post op bleeding & 1 & 0.28 \\
\hline Bile leak & 3 & 0.86 \\
\hline CBD injury & 1 & 0.28 \\
\hline Total & $\mathbf{5}$ & $\mathbf{1 . 4 2}$ \\
\hline
\end{tabular}

One of the patients developed post operative bleeding within 24 hours that necessitated re-exploration. The finding was that of diffuse ooze from Gall bladder fossa that got controlled after packing.

Of the 3 patients with post operative bilioma as diagnosed by abdominal ultrasound, all required re-explorations with subsequent drainage and drain placement due to lack of technical expertise for percutaneous drain placement. However, other complications like retained stones, pancreatitis, wound infection, incisional hernia, pneumoinsufflation or trocar related complications were not encountered in this study. There was no mortality noted.

\section{DISCUSSION}

Since its advent, laparoscopic cholecystectomy has rapidly gained fame and popularity in the surgical circle. Its numerous benefits over the conventional open system has placed it as the preferable procedure of choice to deal with gall stone disease for both elective and emergency situations. ${ }^{13,14}$ Even though the complication rates have long been a matter of debate and discussion, and existence of a steep learning curve is well known, it still remains desirable to attempt laparoscopic approach even in situations where technical difficulties can be anticipated. ${ }^{14}$

In a rural set up like ours, the felt need for this seems to be even more. Due to general lack of awareness and more so about the morbidities and complications of gall stone disease, frequently the presentation is delayed. Lack of easy access to a surgical facility, tendency to seek temporary symptomatic relief and financial constraints all discourage rural members of the society from receiving appropriate and timely treatment. This in turn results in late and complicated presentations and often a surgically difficult gall bladder.

The rural members tend to rely on single source of income which is usually agriculture, household job or daily labor. In such a scenario, a successful laparoscopic outcome, by decreasing overall morbidity and enabling them to return to early activity seems to directly impact their health and socioeconomic status. 
Having successfully accomplished more than 700 laparoscopic cholecystectomies since its introduction in 2006 in our hospital, we tend to approach these conditions laparoscopically.

This study shows that the facility is not just being catered to the Palpa district of Lumbini zone but also to many other surrounding districts. Likewise in the study group, the disease seems to be more prevalent amongst the people belonging to Brahmin ethnic origin which could be related to genetic factors or dietary practices. Our operating time was $<2$ hours for most of the patients which we believe should shorten down without an increase in complication rate with increasing experience. Currently, we tend to approach even an acutely inflamed gall bladder laparoscopically with some success.

However, a certain number of these get converted to open method and for various reasons, mostly guided by their operative findings and technical difficulties. This certainly adds to some morbidity though most authors believe this to be a sign of surgical maturity and most even suggest to maintain a lower threshold for conversions in order to avoid major complications. Never the less, extensive surgical experience in both the laparoscopic and open methods seems to be the key to a safe and successful outcome. We report a conversion rate of $6.9 \%$ which falls within the range described by most series. ${ }^{1}$ Our overall complication rate was found to be $1.42 \%$, of which the most concerning was the common bile duct injury. The rate of this was found to be $0.28 \%$ with most studies reporting a range of 0.4 $0.7 \%{ }^{1}$
The most common complication was that of post operative bilioma $(0.86 \%)$ requiring re-exploration and drainage. This could have been due to a leak from a minor biliary duct at the gall bladder fossa and retrospectively could have been avoided with use of a sub hepatic drain. This is mainly so because we do not routinely do an on table cholangiogram to delineate biliary anatomy and neither is the practice of a routine drain justifiable. Hence, this is a complication that could recur and require re-exploration. Also due to the lack of technical expertise like percutaneous drainage or aspirations, this seems to add some morbidity.

On the whole, we feel that laparoscopic cholecystectomy is the preferable method of choice to deal with gall stone disease even in the rural peripheral set up and can be adopted as a feasible standard having explained the chances of complications and conversions to the patient groups.

\section{CONCLUSION}

Symptomatic gall stone disease is a common presentation in the rural population of western Nepal and accounts for a common reason for hospital admissions. This is also one of the common operations here and was conventionally being performed with open method. With the knowledge about the advantages and superiority of laparoscopic approach over the open, and considering the impact that it holds on the overall outcome, morbidity, health and socioeconomic status of the rural group, we conclude that laparoscopic approach is safe, reliable and a promising option in this set up too. Therefore we recommend it as an acceptable feasible standard in rural peripheral set up.

\section{REFERENCES}

1. Zinner MJ, Ashley SW. Maingot's Abdominal Operations. $11^{\text {th }}$ ed. New York, NY: McGraw-Hill; 2007.

2. Panthee MR, Pathak YR, Acharya AP, Mishra C, Jaisawal RK. Prevalence of gall stone disease in Nepal: Multi Center Ultrasonographic studyNAMS. PMJN 2007;7:45-9.

3. Adamsen S, Hansen $\mathrm{OH}, \mathrm{P}$. Funch-jensen. Laparoscopic Cholecystectomy: A prospective Nationwide series. I Am Coll Surg 1997; 184:571.

4. Kumar S, Patowary BN, Hirachan S, Shrestha P. Laparoscopic Cholecystectomy: An experience at College Of Medical Sciences, Teaching Hospital, Bharatpur. Nepal Journal of College of Medical sciences-Nepal, 2011;7:6-10.

5. Friedman GD. Natural history of symptomatic and asymptomatic gall stones. Am J Surg 1993;165:399.

6. Soper NJ, Stockman PT, Dunnegan DL, Ashley WL. Laparoscopic Cholecystectomy:the new 'gold standard'? Arch Surg 1992;127S: 917-21.

7. Barkun JS, Barkun AN, Sampalis JS. Randomized controlled trial of laparoscopic versus mini-cholecystectomy. Lancet 1992;340:1116-9.

8. Bass EB, Pitt HA, Lillemoe KD. Cost-effectiveness of laparoscopic cholecystectomy versus open cholecystectomy. Am J Surg 1993;165:466-71.

9. McMahon AJ, Russell IT, Baxter JN. Laparoscopic versus mini laparotomy cholecystectomy: a randomised trial. Lancet. 1994; 343: 135-8.

10. Soper N. Laparoscopic Cholecystectomy. Curr Probl Surg 1991;28: 585-655.

11. Soper NJ, Barteau J, Clayman R, Ashley SW, Dunnegan DL. Laparoscopic versus standard open cholecystectomy: comparison of early results. Surg Gynecol Obstet 1992;174:114-8.

12. Bailey RW, Zucker A, Flowers JL, Scovill WA, Graham SM, Imbembo AL. Laparoscopic cholecystectomy. Experience with 375 consecutive patients. Ann Surg. 1991 Oct; 214(4):531-40.

13. Kelley JE, Burrus RG, Burns RP, Graham LD, Chandler KE. Safety, efficacy, cost, and morbidity of laparoscopic versus open cholecystectomy: a prospective analysis of 228 patients. Am Surg. 1993 Jan; 59(1):23-7.

14. Colonval P, Navez B, Cambier E, Richir C, de Pierpont B, Scohy JJ, et al. Is laparoscopic cholecystectomy effective and reliable in acute cholecystitis? Results of a postoperative study of 221 pathologically documented cases. Ann Chir. 1997;51:689-96. 